\title{
La tradición hispanoamericana de la "vida imaginaria": una antología inminente desde Alfonso Reyes a Roberto Bolaño (y un decadente francés)
}

\author{
Cristian Crusat \\ Georgetown University \\ cc1982@georgetown.edu
}

I

Quisiera admitir desde el principio que en el subtítulo de esta conferencia ${ }^{1}$ debería resonar, humildísimamente, el inspirado y sugestivo aserto que el propio Reyes enunció en un ensayo titulado Teoría de la antología, donde se afirma lo siguiente: "Toda historia literaria presupone una antología inminente" (Reyes 137). Además de ayudarme a articular mi propuesta, la frase es pertinente por varios motivos. En primer lugar, porque refleja el carácter caprichoso, aleatorio y, en última instancia, complejo de nuestra relación con los textos. Efectivamente, al portarlos con nosotros, al reinterpretarlos, evocarlos y someterlos a diversas y muy personales asociaciones, estamos afirmando la naturaleza antológica del pensamiento literario, refractario a la rígida imagen del manual de historia literaria, unívoco y clausurado y siempre, por fuerza, selectivo. Como se verá, los libros y autores a los que aludiré aquí forman parte de mi propuesta de una "historia no académica de la biografía" (Crusat 2015), es decir, una delgada vena de mercurio narrativa que atraviesa el género biográfico. Según mis planteamientos, esta particular historia comienza en el siglo III de nuestra era con esa falsa historia de la filosofía que suponen las Vidas de los filósofos ilustres de Diógenes Laercio, se prolonga con los trabajos de John Aubrey, James Boswell, Thomas De Quincey, el decadente Marcel Schwob y se convierte, ya en el siglo XX, en una auténtica tradición hispanoamericana gracias a las aportaciones de Alfonso Reyes -con sus Retratos reales e imaginarios (1920)-, Jorge Luis Borges -con Historia universal de la infamia (1935)-, del pomposo y disparatado heterónimo Honorio Bustos Domecq creado por Borges y Bioy Casares -Crónicas de Bustos Domecq (1967)-, de Juan Rodolfo Wilcock - La sinagoga de los iconoclastas (1972) - o de Roberto Bolaño -con La literatura nazi en América (1996), a mi entender, el gran articulador y resignificador de esta estirpe-.

En segundo lugar, en congruencia con el aserto de Reyes, la propuesta teórica - 0 , más bien, las pistas o huellas teóricas- de Roberto Bolaño (las cuales me permitieron delinear esta tradición) adoptan la forma de una brevísima antología, de una muy escueta enumeración (una perspectiva

\footnotetext{
1 Esta conferencia fue leída en el marco de las actividades desarrolladas por el proyecto FONDECYT Regular No 1150061 "Fábulas biográficas: las vidas imaginarias de la narrativa hispanoamericana" (2015-2017), del que la profesora Lorena Amaro fue investigadora responsable. El texto fue leído el 7 de marzo de 2018 en el Auditorio de Filosofía del Campus Oriente de la Pontificia Universidad Católica de Chile.
} 
complementaria, por cierto, para la formación del canon de autores modernos desde hace varios siglos: así los apuntes sueltos o las listas o relaciones de poetas disfrazados de escrutinios de librerías). Y a mayor abundamiento, el libro con el que Bolaño se integró deliberadamente en esta tradición, La literatura nazi en América, publicada en 1996, representa una antología de biografías de aliento enciclopédico acerca de supuestos escritores filonazis, incluido un certero y detallado apéndice de revistas y de editoriales ideológicamente afines.

\section{II}

En líneas generales, considero que esta tradición hispanoamericana de la "vida imaginaria" representa inmejorablemente el modo en que acontece una historia no académica de la literatura. Caracterizado por un método hermenéutico, el concepto de "historia no académica de la literatura" ha sido planteado desde el 2001 por Francisco García Jurado, catedrático de Filología Latina en la Universidad Complutense de Madrid. Se trata de un concepto que puede definirse, sencillamente, como un tipo de relaciones entre autores de distintas épocas, de carácter dialógico, que van más allá del tiempo y que se articulan según diferentes tensiones, entre las que se plantean las de cosmopolitismo y localismo, conocimiento y opinión, tradición clásica y tradición moderna o autores raros y autores universales. Frente a la limitación que conllevan las ideas de influencia o imitación, este concepto nos recuerda que existen muy diversos y menos limitadores mecanismos a través de los que se perpetúa el diálogo entre autores de distintas épocas y el modo en que se renuevan sus propuestas. Las ideas expresadas por T.S. Eliot en su artículo "Tradition and Individual Talent" de 1920 y por Borges en "Kafka y sus precursores", texto de 1952, consolidaron la idea de que la tradición no tiene un único sentido lineal desde el pasado al presente, ya que el presente puede alterar esa misma tradición al recrearla. Según Borges y Eliot, resulta imposible considerar a un autor de manera aislada; pues los escritores forman parte siempre de un conjunto que ellos mismos modifican mediante su propia inserción dentro del sistema. Esta idea es vital para comprender el funcionamiento de la historia no académica; es decir, para observar cómo cada escritor crea sus precursores, modificando con su labor nuestra concepción del pasado y, de manera simultánea, modificando el incierto futuro.

En un principio, la historia no académica nace de una tensión fundamental a fines del siglo XIX: la que se plantea entre la tradición clásica, acuñación novedosa por aquel entonces, y la emergente tradición moderna. La historia no académica surge entonces para hablar sobre encuentros complejos entre autores antiguos y modernos más allá de la manida idea de una tradición lineal, de un relato demasiado simple que omite aquello que Claudio Guillén denominó "estructuralismo histórico" (1989), cuyo objeto de estudio son los conjuntos o sistemas estructurados. La historia no académica, por esta razón, no puede ser lineal, ni tampoco una mera crónica de anécdotas, sino que atiende a un concepto más rico de la temporalidad. Así, a resultas de las tensiones entre historia y estética, optará por estudiar la configuración de modelos históricos supranacionales cuando la lectura recurrente y transnacional de ciertos autores antiguos pase a verse motivada por las estéticas de la modernidad. Por tanto, la historicidad de la historia no académica de la 
literatura viene definida por diversas tensiones y "brota" de su propia capacidad de elección, de rechazo y de vuelta al pasado en busca de precursores. Así hizo Bolaño con Reyes, con Borges, con Wilcock (a quien el escritor chileno siempre consideró hispanoamericano) y con Schwob. De este modo Borges o Bolaño se convertirán en precursores de Schwob, en precursores de una nueva lectura sobre la escritura biográfica y en precursores, a través de Schwob, de todos aquellos autores que el francés destacó en el prefacio a su libro Vies imaginaires, de 1896, escrito exactamente cien años antes de La literatura nazi en América.

\section{III}

"Bueno: lleguemos a un acuerdo. Lean a Petrus Borel, vístanse como Petrus Borel, pero lean también a Jules Renard y a Marcel Schwob, sobre todo lean a Marcel Schwob y de este pasen a Alfonso Reyes y de ahí a Borges".

Roberto Bolaño, "Números", revista Quimera, 1998.

\section{IV}

Esta cita, extraída de la revista española Quimera, constituye un ejemplo práctico de esa espontánea y compleja capacidad de elección de una tradición literaria. Y repito: la historicidad de esta historia no académica "brota" de su propia capacidad de elección, de rechazo y de vuelta al pasado en busca de autores. Entre otros mecanismos, podemos reconocer en la enumeración de Bolaño el alineamiento con una determinada nómina de autores o la creación de un espacio propio desde el que ser leído correcta o favorablemente. Nada nuevo para los lectores ni los escritores. Tan solo una manifestación fundamental para el concepto de "historia no académica": en este caso, que la historia literaria no es un concepto apriorístico ni ajeno a la propia creación, pues ella misma también puede ser objeto de esta.

En efecto, desde el siglo XIX fue constatable una acendrada reacción en numerosos autores, especialmente franceses, en relación con el nuevo contexto filológico y universitario de la época, definido por la creación de cátedras universitarias de historia literaria. Este fenómeno dio lugar a un nuevo panorama historiográfico, patrocinado por el favor constitucional, que procedió a instaurar cátedras de historia literaria, las cuales, por un lado, necesitaban profesores $y$, por otro, motivaron la proliferación de programas de clase y manuales. Frente a las exclusiones y omisiones de autores, frente a los connotados repudios estéticos, respondieron autores como Joris-Karl Huysmans: recuérdese que en su obra À rebours, de 1884 -traducida como A contrapelo o Al revés- el protagonista, Jean Des Esseintes, invierte los cánones de la literatura latina a partir de manuales auténticos de Alfred Ebert o Desiré Nisard. Claramente, Huysmans se proponía así "desmontar" la interpretación oficial de la historia de la literatura latina para ensalzar la Decadencia frente al Ilamado Siglo de Oro, en claro paralelismo con lo que ocurría en su propio mundo literario y finisecular. Además de Huysmans, Charles Baudelaire y Marcel Schwob, entre otros, encarnan esa incomodidad que los juicios de la academia habían comenzado a suscitar entre los autores a fines del siglo XIX. 
En esos últimos años del siglo XIX se publicó Vies imaginaires, de Marcel Schwob, auténtica piedra de toque de esta tradición para Roberto Bolaño y manifestación, asimismo, de esa reacción contra la nueva disciplina historiográfica que se abría paso en las aulas universitarias. De este modo hay que interpretar la inclusión de autores como Lucrecio, Catulo o Petronio en el conjunto de Schwob, que incluye personajes de toda la Historia: Antigüedad, Edad Media y siglos XVII y XVIII. Aunque no se ciñe únicamente a escritores, Schwob es muy consciente -cuando elige entre sus biografiados a autores literarios- de estar reivindicando y enunciando una historia literaria alternativa, pues presenta a autores y recurre a textos que no pertenecen al canon escolar, ya por ser poco conocidos (por ejemplo, la epigrafía funeraria de carácter popular), por tratarse de obras que muestran aspectos sórdidos (los poemas de Catulo), explicaciones materialistas de la realidad (Lucrecio), o que la historia oficial de la literatura tacha de decadentes (la novela de Petronio). El caso de Petronio es especialmente relevante por cuanto no solo reivindica la estética decadente de su Satiricón, sino porque a través de su biografía Schwob introduce un vaivén entre ficción y realidad que permeará las biografías escritas por Borges, Bolaño y compañía. Desmintiendo en su "vida imaginaria" de Petronio la fuente historiográfica de Tácito, según esta, Petronio se abrió las venas, Schwob imagina otra muerte bien distinta para el autor del Satiricón, concediéndole una larga vida errante cuyos episodios serán consecuencia de lo escrito en su propia novela. Frente a lo esperable, donde la literatura es consecuencia de la vida (es decir, la novela de Petronio concebida como el resultado de sus propias experiencias vitales), aquí la novela escrita servirá de modelo, a priori, para la vida, que será, pues, una consecuencia de la propia literatura. Resulta lógico el interés que esta historia de Schwob despertó en un autor como Enrique Vila-Matas, quien la recuerda en Bartleby y compañía (y luego en su relato "Porque ella no lo pidió", incluido en Exploradores del abismo) y la resume como "la historia del escritor que se atreve a vivir lo que ha escrito y por eso deja de escribir" (Vila-Matas 2011 202).

V

En lo esencial, Vies imaginaires de Marcel Schwob, aparecido en 1896, se convirtió en el siglo XX en una referencia según la cual era posible ensayar un tipo de biografía breve y alejada de la veracidad documental y de las servidumbres propias del historiador. El hallazgo de este autor francés, y la razón de su fortuna entre estos escritores hispanoamericanos, consistió en la elaboración de una Historia individualizada de la humanidad, única y ajena a cualquier paralelismo de raigambre plutarquea. Mediante veintidós breves biografías, Vies imaginaires personifica el espíritu humano en los destinos, a menudo inventados o mistificados, de un puñado de seres humanos. Y esto es lo que caracteriza la escritura biográfica de Marcel Schwob: su atención por los detalles individualizadores, su desdén por la verdad histórica y su brevedad. En el prólogo a Vies imaginaires, el autor procedió a deslindar tajantemente los ámbitos del arte y de la Historia, localizando su propuesta biográfica dentro del campo de gravedad artística. Sobre la base de estas afirmaciones, el escritor de biografías no es considerado un historiador y, por lo tanto, la veracidad se convierte en un aspecto secundario y aun irrelevante. Además, debido a que la Historia no es el ámbito 
exclusivo de su trabajo, el biógrafo está en la obligación de extender su labor más allá de los personajes célebres, ilustres o reputados. En el compendio de Schwob, junto a figuras históricas como Eróstrato, Crates, Petronio, Lucrecio, Cecco Angiolieri, Gabriel Spenser o Pocahontas, se encuentran, encarnando diferentes épocas, personajes anónimos o inventados por el autor de Vies imaginaires. De un único, ágil y apresurado vistazo -gracias a las veintidós escuetas biografías-Schwob resume las grandes etapas de la Historia, combinando pensamiento e imaginación, arte y filosofía: además de escenas de erotismo mórbido, las biografías imaginarias incorporan numerosos elementos oníricos y visionarios.

He ahí tres características fundamentales de este microgénero de la "vida imaginaria" (García Jurado 2008 47): a) brevedad, pues lo anecdótico, lo mínimo y lo esencial se convierten en una máxima estilística; se eligen momentos decisivos; b) elementos visionarios, oníricos o sórdidos, lo cual convierte a las "vidas" en textos iniciáticos o crípticos; y c) al recrear vidas de escritores, resalta el carácter metaliterario de las "vidas", pues sus biografías van a confundirse deliberadamente con sus propias ficciones, como en el caso antes expuesto de Petronio o, incluso, se producen transferencias entre el autor -Schwob- y algunos personajes -es el caso de Lucrecio, donde se aborda el tema de la impotencia masculina-.

Las "vidas" de Schwob, en suma, se erguirán así como una exploración de la escritura y de los problemas de articulación de un mundo todavía por hacer e interpretar. Búsqueda de lo individual y de lo único, de las anomalías cotidianas y los rasgos singulares de sus protagonistas, el proyecto biográfico de Schwob rehúye con firmeza el estilo del historiador, decantándose por la inventiva y las dotes fabuladoras del cuentista, del narrador. En su tarea de resumir la vida de un hombre asume que, en su extrema individualidad, constituye el mayor y el más oscuro secreto de todos cuantos habitan este extraño mundo.

\section{VI}

Estas últimas características llamaron intensamente la atención de los autores que más tarde se convirtieron en precursores de Schwob, a quien salvaron de su condena a convertirse en una palabra de cualquier índice sobre literatura fin de siècle. Gracias a esta relectura de Borges y de Bolaño en el siglo XX, Schwob se proyectó por distintos cauces en las obras de numerosos autores y se alzó como un autor de singular alcance.

Pero volvamos a los consejos de Bolaño: "Sobre todo lean a Marcel Schwob y de este pasen a Alfonso Reyes y de ahí a Borges". El relato parece lineal, pero solo lo es en apariencia. Recuerden que estamos trazando una historia no académica. Y recuerden que su historicidad "brota" de su propia capacidad de elección, de rechazo y de vuelta al pasado en busca de precursores, un asunto al que Borges contribuyó notablemente.

Aunque Jorge Luis Borges publicó Historia universal de la infamia, su primer libro de narraciones, en 1935, el escritor argentino no reconoció hasta mucho más tarde los vínculos temáticos que su propia obra guardaba 
respecto a Vies imaginaires. Ocurrió gracias a la aparición de libros como el de Schwob en la colección Biblioteca personal Jorge Luis Borges, publicada por la editorial Hyspamérica en 1987, la cual -merced a los escuetos prólogos dedicados a sus heterogéneas preferencias lectoras- delinea las fronteras de la particular república de las letras borgeana. Entre las obras allí sancionadas se encontraba la obra de Schwob (Borges 2011): "Hacia 1935 escribí un libro candoroso que se llamaba Historia universal de la infamia. Una de sus muchas fuentes, no señaladas aún por la crítica, fue este libro de Schwob". Sencillamente, Borges invitó a los lectores a enfrentarse a un distinto horizonte de expectativas en relación con Marcel Schwob: no ya como un escritor anecdóticamente encasillado en uno de los múltiples y a menudo indefinidos reflujos románticos del siglo XIX (simbolismo y decadentismo especialmente), sino como un autor de alcance, vocación y sensibilidad singulares, exquisito -"escribió deliberadamente para los happy few, para los menos"-, dotado de hondas erudición y conciencia de la historia literaria - "Siempre fue suyo el ámbito de las profundas bibliotecas"- y, en suma, como el emblema de una literatura para iniciados y como encarnación de lo estrictamente literario: "En todas partes del mundo hay devotos de Marcel Schwob que constituyen pequeñas sociedades secretas". Pero la principal razón por la que Borges acudió al conjunto de biografías de Schwob fue porque encontró en ella el tipo de literatura biográfica e histórica que buscaba escribir con Historia universal de la infamia: repleta de canallas y de delincuentes; sórdida, ridícula y desprovista de cualquier propósito edificante o moral. A este respecto, debería recordarse que los libros, por lo general, no son solo lo que dicen o aparentan decir, como afirmó Antonio Tabucchi, sino que incluyen asimismo "todo lo que otras personas buscarán en su lectura" (Gumpert 57). Borges buscaba una literatura biográfica y Schwob, un autor etiquetado frecuentemente como simbolista, se la proporcionó, convirtiéndose en el punto de partida de una tendencia sobresaliente de la literatura del siglo XX.

\section{VII}

La revalorización de la obra de Marcel Schwob a lo largo del siglo XX representa un magnífico ejemplo de cómo la actividad lectora se alza como un condicionante fundamental del cambio literario. Arrinconado en el apolillado cajón de los escritores simbolistas, Schwob cayó en el olvido pronto, muy pronto. Tras su muerte, acaecida en 1905, su nombre dejó de circular. ¿Cómo, entonces, se convirtió ese mismo autor francés, enfermizo y de obra breve en el emblema de lo literario, especialmente para autores que escribían en español? Fundamentalmente por la repercusión que las ideas de querella, duelo y enfrentamiento, anejas a la noción de república literaria, tuvieron en la obra de Borges, como ha subrayado Alan Pauls: "En rigor, toda la literatura de Borges podría leerse como un gran manual sobre las distintas formas del diferendo, desde la querella intelectual o erudita (....) hasta el enfrentamiento físico de un duelo a cuchillo o un hecho de sangre, pasando por el célebre motivo del doble, una variante con la que Borges suele traducir las relaciones de rivalidad a la esfera más o menos universal de la metafísica" (Pauls 39).

Así pues, Borges ha obligado a leer toda esta tradición de la "vida imaginaria" (es decir, la obra de Marcel Schwob y la de los precursores del mismo 
Schwob, que este señaló en el prefacio a Vies imaginaires -Diógenes Laercio, Aubrey, Boswell-, y la de quienes después de Schwob y de Borges cultivaron este microgénero) a partir de las claves que establecen las narraciones de Historia universal de la infamia, esto es, desde un nuevo paradigma de posibilidades: desde la ironía, el ocultamiento y la falsificación de otras obras literarias, los comportamientos desaforados o extravagantes de sus personajes y, por supuesto, desde el sentido del humor y la introducción de numerosas bromas privadas. Al componer este tipo de biografía, los autores hispanoamericanos no hacen más que aproximarse, aunque de un modo innovador, a la principal pregunta que ocupa a la literatura: qué es una vida, la vida, qué puede ser, y cómo se convierte en literatura. Naturalmente, la siguiente pregunta será cómo articular históricamente todas estas relaciones; esta combinación de imaginación, historia, sueños y mixtificaciones.

\section{VIII}

Junto a las características de brevedad, carácter onírico, visionario o sórdido y metaliterario de las "vidas" de Schwob, la tradición hispanoamericana incorporará nuevos y genuinos atributos a sus biografiados. Entre ellos, la excentricidad. Esto es apreciable, sobre todo, en el estrafalario comportamiento de los protagonistas de Crónicas de Bustos Domecq y en la pareja de sucesores de la estela desaforada y vanguardista creada por Jorge Luis Borges y Adolfo Bioy Casares: La sinagoga de los iconoclastas, de Juan Rodolfo Wilcock - plagado de inventores, utopistas y eruditos obsesivos- y La literatura nazi en América, de Roberto Bolaño -donde figuran literatos menores filonazis, excesivos y a menudo vanguardistas-. Lo que particulariza la conducta excéntrica de estos seres, frecuentemente, puede resumirse en el hecho de querer llevar la razón de cualquier argumento o hipótesis hasta sus últimas consecuencias. De este modo se lleva al extremo una de las sugerencias de Marcel Schwob referente a la descripción de las rarezas y anomalías del biografiado. Dijo en su prefacio: "El libro que describiese a un hombre con todas sus anomalías sería una obra de arte como la estampa japonesa en la que puede verse eternamente la imagen de una pequeña oruga atisbada en una ocasión, a una hora particular del día" (Schwob 84).

La ironía, por lo demás, será otro estilema asociado a esta tradición. Gracias al humorismo, Borges pudo acometer la heroización extravagante (estilística, aunque no moral) de personajes cuya conducta fue dirigida por el oprobio y la villanía. Logró abordar la infamia desde una perspectiva estilística y desenfadada, alejada de la lectura moral de los hechos y, como había referido Schwob, desde cierta superioridad escéptica ante las acciones insensatas que se narran, pero al mismo tiempo crítica con una época convulsa en Argentina: la publicación de la Historia universal de la infamia acontecerá, además, en una década en la que en Argentina se expande un descreimiento generalizado en las instituciones, amén del fraude electoral, un periodo conocido entre 1930 y 1943 como la "Década Infame". Esta misma senda será la que transiten el propio Borges y Bioy Casares, así como Wilcock y, finalmente, Bolaño: la de la deformación, la ironía y la sátira de los temas culturales y literarios propios de la modernidad, por un lado, y de la exageración grotesca de los excesos tecnocráticos y totalitarios del siglo $\mathrm{XX}$, por otro. 
Por último, en lo referente al carácter metaliterario, dicha particularidad resulta indudable en el caso de La literatura nazi en América de Roberto Bolaño, donde la vida de los protagonistas se confunde con los propósitos de su propia obra, subordinándose a sus empeños y anhelos literarios, así como en los vanguardistas de Crónicas de Bustos Domecq, de Borges y Bioy Casares. De todas formas, concurre en este apartado un nuevo fenómeno, muy relevante: el hecho de encontrarse ante una historia literaria alternativa respecto a la oficial se traslada, palpablemente, de los personajes de ficción -como en el Petronio retratado por Schwob- a los propios autores de las obras. Ya no se trata únicamente de insertar a un literato y conjugar ficticiamente su vida con su quehacer creativo, sino de que los autores reales, aquellos que firman los libros, se integran voluntaria y decididamente en una estirpe literaria. En consecuencia, la tarea de escribir y publicar una obra de tales características, inspirada sin duda en las Vies imaginaires de Marcel Schwob (y en lo que la convirtió la relectura de Borges, es decir, en esa contraseña literaria), representa una verdadera toma de posición por parte de sus sucesores, sobre todo por parte de Wilcock y Bolaño, conscientes de las alteraciones introducidas en el modelo original tras la relectura borgesiana de la "idea" de Marcel Schwob. En esta clave puede leerse la irónica cita inicial de Augusto Monterroso con la que se abre el último eslabón de esta cadena, La literatura nazi en América: "Cuando el río es lento y se cuenta con una bicicleta o caballo sí es posible bañarse dos (y hasta tres, de acuerdo con las necesidades higiénicas de cada quien) veces en el mismo río" (Bolaño 2005 9). En este sentido, el río no sería otro que la tradición de la "vida imaginaria".

Mediante este mecanismo estratégico, los autores manifiestan su solidaridad con una pequeña tradición -creada y desarrollada por los propios continuadores y, más en concreto, por Jorge Luis Borges- cuyas obras se consagran, en especial, a la erudición, la brevedad, la ironía, la excentricidad y a una resuelta amalgama de ficción y realidad en sus creaciones literarias. De este modo, la excentricidad anteriormente aludida es doble: en primer lugar, porque los autores configuran en sus synagogés biográficas una galería de personajes estrafalarios y excesivos. Y, en segundo lugar, porque ellos mismos deciden emplazarse en un microgénero alejado del canon tradicional - del centro, esto es, del género biográfico al uso- y relativamente novedoso, para cuyo análisis son necesarios unos métodos que tengan en cuenta las particularidades ontológicas de sus personajes. Como dice Vila-Matas: "Extravagancia, pues, entendida como la transformación de uno mismo en "un personaje literario". Vida y literatura abrazadas como el toro al torero y componiendo una sola figura, un solo cuerpo" (Vila-Matas 2008 80-81).

\section{IX}

Roberto Bolaño, por su parte, trasladó a sus obras de manera arrolladora las complejas luchas que, pocos años antes de escribir Schwob sus Vies imaginaires, Baudelaire había instaurado contra los discursos oficiales literarios y pictóricos, las cuales se englobaban en su objetivo más general de afirmar la independencia social del artista. Resulta obvia la imbricación entre política y literatura que recorre toda la obra de Bolaño, en contraste con la idea falsa y generalizada de que el conocimiento "puro", humanista 
o artístico, es fundamentalmente no político, como se encargó de recordarnos Edward W. Said en su célebre Orientalism (1978). La obra de Bolaño -y La literatura nazi en América en particular- se ve atravesada por todo el conjunto de significaciones que supone la penetración de la sociedad política dentro de los dominios de la sociedad civil, representada en este caso por un sistema literario estructurado según la oposición entre beneficio comercial y prestigio artístico, el mismo que existe desde que Baudelaire interviniera en el campo literario francés de su época y de que Pierre Bourdieu lo analizara con tanta claridad en su libro Les regles de l'art (1992). Al redefinir radicalmente el papel del crítico, el autor de Les fleurs du mal (1857) participa en la constitución de un campo en el que cada creador está legitimado para instaurar sus propias reglas en relación con la obra de arte (incluida, por supuesto, la tradición a la que quiere pertenecer). Y en esto Bolaño fue muy claro: tenía que ser una en la que, como dijo en aquel artículo de 1998, estuvieran Schwob, Borges y Reyes, cada uno por distintos motivos. Escribir "vidas imaginarias", en mi opinión, lo situó definitivamente en esa tradición.

De la tradición aquí escuetamente delineada, La literatura nazi en América es el libro que encierra un mayor número de referencias directas a la política de su tiempo y a las dictaduras hispanoamericanas de todo el siglo XX, subrayando la complejidad de los procesos de la modernidad ilustrada y su demostrada capacidad destructiva. Si en La sinagoga de los iconoclastas de Wilcock la ironía impugna la deriva cientificista del siglo XX, en La literatura nazi en América descuellan las obscenas vinculaciones entre el arte y los totalitarismos.

Dentro de un ejercicio de brevedad como la narración de un puñado de "vidas imaginarias" de escritores filonazis, Roberto Bolaño pondrá en juego elementos propios de la poética de la summa que caracteriza toda su obra: una estructura coral y genealógica, largas enumeraciones y listas. Así, entre lo uno y lo diverso, Roberto Bolaño abundará en descripciones detalladas, listas interminables y extensos inventarios de revistas, editoriales y personajes.

Las treinta biografías distribuidas en trece breves capítulos corresponden a autores ficticios de diferentes puntos del vasto continente americano. Argentina, Colombia, Brasil, Cuba, Perú, Chile, México, Venezuela, Uruguay y Guatemala son los países de origen de los autores hispanoamericanos. De Norteamérica provienen siete literatos y de la ciudad de Puerto Príncipe, el gran maestro en el arte del heterónimo y del plagio, Max Mirabelais (alias Max Kasimir, Max von Hauptman, Max Le Gueule o Jacques Artibonito). Lo que en un principio adopta la forma de una exhaustiva antología de escritores queda rápidamente desmentido si se observa con atención la cronología vital de los mismos, cuyas fechas de fallecimiento ocurren en 2014 o 2021, décadas después de la publicación original del libro. El tono de las narraciones remite al estilo rotundo e hiperbólico de Bustos Domecq y a los comentarios absurdos del narrador del libro de Wilcock. Por ejemplo: "La lectura de Norman Spinrad y de Philip K. Dick y tal vez la posterior reflexión sobre un cuento de Borges llevaron a Harry Sibelius a escribir una de las obras más complicadas, densas y posiblemente inútiles de su tiempo" (Bolaño 2005 130). Sin duda, esta alusión de Bolaño recuerda a las que caracterizan al 
narrador de Wilcock en La sinagoga de los iconoclastas, de uno de cuyos personajes, André Lebran, por ejemplo, se dice que "es recordado, modestamente recordado, o mejor dicho no es recordado en absoluto, como inventor de la pentacicleta o pentaciclo, o sea la bicicleta de cinco ruedas" (Wilcock 92). Con un par de trazos, Bolaño instala al lector en ese reconocible ámbito de proyectos inservibles y personalidades ineptas de la escritura de Borges, creador de una identificable familia de imbéciles y personajes-border (Pauls 151) y, por supuesto, inspirador de muchos otros personajes de la misma ralea intelectual.

El narrador de la obra de Bolaño, advierte el lector poco a poco, está tan loco como sus antologados, como cuando se refiere a Zach Sodenstern, supuesto autor de ciencia-ficción, y al perro de este, Ilamado Flip: "En una nota suelta en su ordenador Sodenstern sugiere que el nuevo mesías podría ser el hijo de Flip, pero todo hace pensar que fue un apunte sin mayor trascendencia" (Bolaño 2005 117). Recordemos el estilo de Bustos Domecq, tan pagado de sí mismo y ridículo en sus apreciaciones en torno a ese clan de incompetentes cuyas obras reseña y aun sobre cualquier aspecto de la vida cotidiana, verbigracia un sencillo viaje a Uruguay: "Si bien el examen del mapamundi no dejó de alarmarme, las seguridades, dadas por un viajero, de que los habitantes del Uruguay dominan nuestra lengua, terminó por tranquilizarme no poco" (Bioy Casares y Borges 38). Lo consabido (y se incluye en esta categoría toda una tradición cultural) se convierte en un desquiciante misterio $y$, narrativamente, en una inagotable fuente de malentendidos y jocosas ocurrencias.

El carácter metaliterario y sórdido de las biografías de La literatura nazi en América puede resumirse en el ejemplo de Rory Long. Fundador de la Iglesia Carismática de los Cristianos de California, obeso predicador cuyo mensaje transmitía mediante sus poemas, Long es el autor de un poema en donde Leni Riefenstahl hace el amor con Ernst Jünger, una nueva amalgama entre la esfera política y la literaria. La cópula entre Riefenstahl y Jünger adquiere dimensiones visionarias para Rory Long, como si el resultado del coito fuera a engendrar una nueva especie o, en cualquier caso, y al igual que sostenía el nacionalsocialismo, una depuración de la raza humana. Se dice en el libro de Bolaño: "Y algunas noches [Rory Long] creyó tocar con la punta de los dedos el cuerpo del Hombre Nuevo. Adelgazó 20 kilos. Ernst y Leni follaban en el cielo para él. Y comprendió que aquello no era una vulgar, aunque candente, terapia hipnótica, sino la verdadera Hostia de Fuego" (Bolaño 2005 155-156).

Al igual que en Los detectives salvajes, 2666 y varios de sus cuentos y novelas cortas, Bolaño va a situar como figura principal de la ficción al poeta, una suerte de héroe que vive en el delirio, incapaz de afrontar la vida si no es desde una afiebrada estética de vanguardia: "[...] el poeta que tiene la ilusión o que vende la mentira de que la literatura actual se puede exterminar para volverla a inventar" (Domínguez Michael 97). Es así como se puede comprender las existencias que se presentan, todas ellas recubiertas por el desquiciante mito de la cultura en el siglo XX. O el brasileño Luiz Fontaine Da Souza, en cuya refutación de Hegel confunde al filósofo alternativamente con Kant, Jean Paul, Hölderlin y Tieck. Es lo 
que ocurre, parece decir el autor, cuando el arte ocupa todas las esferas de la vida, cuando no existe más ética que la Forma y cuando el artista (y su antólogo), en la línea de los personajes inventados por Borges y Bioy Casares, es un auténtico incompetente.

La literatura nazi en América se alza como el mejor ejemplo de la permanente imbricación entre política y literatura que tiene lugar en la obra de Roberto Bolaño. El hecho de que algunos lugares de Latinoamérica dieran cobijo a refugiados nazis o de que en ese mismo subcontinente se multiplicara el número de Estados totalitarios forma parte de una desilusión política a la que la literatura nuevamente debe hacer frente y de la que no puede escapar. El fracaso político, en este caso, se alza también como un fracaso literario, encarnado en un buen número de artistas cómplices con ese tipo de regímenes y políticas, evidenciándose que el arte no representa ninguna garantía contra el horror. Sí representa, no obstante, el mayor desafío para cualquier escritor, en opinión de Bolaño: el de saber convertirlo en literatura ( $y$, más concretamente, en auténtica literatura de vanguardia).

En consecuencia, La literatura nazi en América hace uso de la ironía para presentar a estos autores de vidas desaforadas y obras literarias de argumentos enrevesados: la vida en la Tierra como resultado de fallidos concursos televisivos intergalácticos (en "Carlos Hevia"), descripciones de campos de concentración e innúmeras variantes sobre un cercado de alambre (en "Willy Schürholz"), conversaciones de temas diversos con la sombra de Goering en un aeródromo venezolano (en "Franz Zwickau"), sagas que imaginan un Cuarto Reich (en "Zach Soderstern")... Encontramos asimismo muertes ridículas o paródicas que resumen de forma grotesca lo exagerado de la ideología de estas vidas -como las del argentino Italo Schiaffino al escuchar uno de los últimos partes de la guerra de las Malvinas o la de Walter Rauss mientras seguía el partido de fútbol que enfrentó a las dos Alemanias en el Mundial de 1974-.

En suma, Bolaño sistematizó y empleó para La literatura nazi en América su modelo formal básico: la biografía. Como ha recordado el escritor Andrés Ibáñez (2014): "El hecho es que Bolaño no piensa por situaciones, como Hawthorne, ni por escenas, como Chéjov, ni por imágenes, como Nabokov. Lo que hace, sobre todo, es contar la vida de una persona, y luego la de otra, y luego la de otra. [...] A veces se cuenta una vida desde el principio, en otras ocasiones Bolaño se limita a presentarnos un personaje, sus circunstancias, sus amores, sus aficiones, sus manías. Sin embargo, es el modelo principal, y lo que nos ayuda a comprender, quizá, la estructura profunda de la vasta obra de Bolaño: una inmensa colección de vidas".

\section{$\mathbf{X}$}

\section{¿Y Reyes?, ¿y sus Retratos reales e imaginarios?}

En síntesis, el volumen de Alfonso Reyes aparece integrado por Roberto Bolaño en una tradición con la que mantiene numerosas divergencias. Su apego documental y las digresiones vinculadas con la actualidad-además de su cercanía con el panegírico en algunos casos y con la información en otros-, 
le distancian del resto de autores, tanto anteriores como posteriores, que se adscriben al modelo narrativo de la "vida imaginaria". Los retratos de Alfonso Reyes se acercan en mayor medida a la semblanza y a la "crítica estética" de Walter Pater que al relato imaginario de Marcel Schwob, es decir, son textos en los que predomina el análisis de la obra sobre el aspecto biográfico del autor o, en cualquier caso, textos en los que ambas categorías, vida y obra, están estrechamente vinculadas (Schwob abordó la vida de autores como Lucrecio o Petronio sin hacer ninguna mención a sus libros). En los retratos de Alfonso Reyes la historia interna de los personajes pierde peso en favor de los hechos constatables, escaseando asimismo los episodios oníricos o misteriosos. No obstante, su presencia responde a la estrategia de Bolaño de identificación con una línea "dura" de la literatura hispanoamericana del siglo XX: maestro reconocido de Borges, Reyes integra la estirpe de Bolaño en su condición de estilista, pero también de representante máximo de la literatura mexicana, una literatura a la que el autor de La literatura nazi en América estuvo vinculado siempre de forma sentimental y a la que convirtió en tema principal de varias obras, entre ellas, fundamentalmente, sus novelas Los detectives salvajes y Amuleto.

\section{$\mathbf{X I}$}

Igualmente México se puede considerar la segunda patria de Schwob, y también puede afirmarse que Schwob impregnó la literatura hispanoamericana desde el Ateneo de México, una institución de existencia breve pero cuya relevante y próspera significación superó con creces las limitaciones territoriales de su país. Rafael Cabrera, un hermano menor del Ateneo, fue el autor en 1917 de la primera traducción al español de La Croisade des enfants [La cruzada de los niños] (1896) de Marcel Schwob, una traducción que dedicó precisamente a su camarada Julio Torri, quien lo había iniciado en el conocimiento del francés (como Cabrera reconoció al comienzo de su traducción de otra obra de Schwob, los Mimos). En su ensayo "La literatura fantástica en México", incluido en el volumen Literatura y vida, Augusto Monterroso se refirió a este curioso fenómeno aludiendo a que Torri y otros escritores coetáneos de principios de siglo "habían recibido a su vez la benéfica y silenciosa herencia de Charles Lamb, Marcel Schwob y Aloysius Bertrand" (Monterroso 92). Los textos "Epitafio" y "Sinesio de Rodas", del mexicano Juan José Arreola, incluidos en Confabulario, de 1952, dan fe de esa continua relectura mexicana de Schwob.

No podemos olvidarnos de la labor de José Emilio Pacheco o de Sergio Pitol, traductor este asimismo de una sobresaliente reescritura de La cruzada de los niños realizada por el autor polaco Jerzy Andrzejewski en la novela Las puertas del paraíso, libro de 1960 de idéntico tema al de Schwob y escrito en una sola frase, con la única salvedad de que es una cruzada de jóvenes que, en lugar de estar guiados por la piedad, parecen estarlo por el deseo sexual adolescente.

Ambos libros, ambas cruzadas narradas por Schwob y Andrzejewski, se convierten en la clave literaria de un libro como Amuleto, originalmente publicado por Bolaño en 1999. Se trata, como es obvio, de un capítulo desgajado de la peripecia general de Los detectives salvajes donde-desde 
el punto de vista de Auxilio Lacouture- la imagen de la cruzada alude a la incierta trayectoria de una nueva generación de jóvenes poetas y a las turbulencias que sacudieron la política de diversos países latinoamericanos, fundamentalmente México y Chile: "Y aunque el canto que escuché hablaba de la guerra, de las hazañas heroicas de una generación entera de jóvenes latinoamericanos sacrificados, yo supe que por encima de todo hablaba del valor y de los espejos, del deseo y del placer. $Y$ ese canto es nuestro amuleto" (Bolaño 2011 154).

Yo mismo he señalado las convergencias obvias entre Los detectives salvajes y La cruzada de los niños de Marcel Schwob (Crusat 2009 y 2015), dado que el método de composición es esencialmente el mismo: numerosas voces narrando su propia historia mientras se desarrolla -indudablemente piadosa en el caso de Schwob, monstruosamente en Los detectives salvajes- la verdadera historia. La yuxtaposición de los ocho relatos en el libro de Schwob motivó la denominación, por parte de Gilles Deleuze y Félix Guattari, de "mesetas narrativas", esto es, fracciones textuales inmanentes y de valor intrínseco, conectadas a otras mesetas por medio de diminutas microfisuras, como ocurre en el cerebro humano. En su reivindicación de una Nomadología (la cual redunda en el énfasis sobre las figuras errantes que se dan cita en toda la obra de Schwob), Deleuze y Guattari subrayan la singularidad de La cruzada de los niños (así como de la reescritura de Andrzejewski en Las puertas del paraíso), elevándola a epítome de escritura nómada: la nomadología, así, como lo contrario de la historia, considerada esta como un instrumento al servicio del aparato unitario y sedentario del Estado.

La impronta de Schwob en Bolaño, en última instancia, desborda el ejemplo de La literatura nazi en América. Es también el germen estructural de Los detectives salvajes y de Amuleto (donde es nombrado como clave literaria), y aparece asimismo en Monsieur Pain y en 2666 y en varios artículos: en definitiva, Bolaño convirtió a Schwob en un clásico cotidiano, al igual que Piero Moroni, el crítico de 2666, de quien se dice en un momento dado, tras la narración del famoso viaje a Samoa, que admiraba a Schwob -"aunque más que admiración era cariño" (Bolaño 2004a 144)-.

\section{XII}

Concluyo. Bolaño hizo de Schwob un "clásico cotidiano" (García Jurado 2001 153), otro concepto que ayuda a comprender cabalmente esta historia no académica. Como tal, Schwob se convierte en un clásico que no viene determinado por un manual o un libro de texto específicos, sino por una lectura relevante y gozosa ( $y$, por ende, una experiencia vital; Bolaño pondera a Schwob porque se aviene a esa figura que el chileno tanto celebró: la del artista heroico y visionario; Schwob el traductor del libro de Thomas De Quincey que Borges quería que le leyeran en su lecho de muerte; Schwob el narrador cuyas ediciones manosea Juan García Madero en Los detectives salvajes; Schwob el viajero que a punto está de perder la vida en el océano por visitar la tumba de Robert Louis Stevenson); la figura de Schwob, en suma, resulta mucho más afín a una biblioteca personal de lecturas -establecida por el azar, el placer y los gustos personales del lector- que a un rígido e impositivo canon, del que en un principio Schwob fue excluido por 
decadente y por formar parte de lo que Mario Praz denominó "romanticismo negro", definido por su inclinación por las conductas sádicas, la perversidad y la mórbida sexualidad (Praz 13). Schwob pudo significar lo que Alfonso Reyes representa para el entusiasta Juan García Madero de Los detectives salvajes, quien llega a afirmar: "Por la tarde, mientras ordenaba mis libros en el cuarto, he pensado en Reyes. Reyes podría ser mi casita. Leyéndolo solo a él o a quienes él quería uno podría ser inmensamente feliz" (Bolaño 2004b 103-104). Según Bolaño, leyendo a Schwob y leyendo a quienes él quería (pero también, añadamos, a quienes lo quisieron y escribieron "vidas imaginarias") uno puede ser un lector inmensamente feliz. Quienes lo leyeron de una manera tan adecuada lograron resignificar el arte biográfico y convertir a Schwob en uno de sus pilares modernos. Es el punto en el que se anuda la historia no académica de la biografía, en cuya conformación coadyuvan varias tensiones, entre ellas la que se genera entre la opinión informada y el conocimiento canónico. Para ilustrar esta tensión, el crítico inglés Frank Kermode expuso en 1985 el caso de la revalorización del pintor Botticelli gracias a la opinión de otros artistas del siglo XIX como Ruskin, Swinburne o Proust, y no principalmente por teóricos de la pintura. La opinión, en este sentido, se alzó como una instancia formadora del canon: "Ahora, firmemente establecido en su nuevo escenario, Botticelli fue situado en un lugar de privilegio del cual nunca sería desalojado por completo. Su promoción la debía no a los eruditos sino a los artistas y otras personas de sensibilidad moderna, cuyas ideas sobre la historia eran más pasionales que precisas y cuyo conocimiento estaba [...] lejos de ser exacto. En este punto, el conocimiento exacto no tenía ningún papel que jugar. La opinión, hasta cierto punto informada, requería, en este momento moderno, un cierto tipo de arte de comienzos del Renacimiento; Botticelli [...] lo proporcionó. El entusiasmo era más importante que la investigación; la opinión, más que el conocimiento" (Kermode 24). Del mismo modo se formó un nuevo canon biográfico alternativo en el siglo XX, gracias a la opinión entusiasta de Borges y Bolaño, fundamentalmente, quienes contribuyeron a crear una tradición propia y singular que, además, ha conseguido traspasar distintos contextos y culturas, lo cual ha llevado a Jill Levine (1973) a calificarla de "universal" (Ios nombres de Antonio Tabucchi, Danilo Kiš o Pierre Michon deberían ser convocados aquí con toda justicia). Esta tradición, además, ha servido para cuestionar, a través del género biográfico, el curso unitario de la Historia. Como sostenía Walter Benjamin en su Tesis sobre la filosofía de la historia, la historia como curso unitario no era más que una representación del pasado construida por los grupos y clases sociales dominantes. Los hechos que se transmiten del pasado no serían todo lo que ha ocurrido efectivamente, sino lo que pareció relevante al autor de su relato -punto de partida para la escritura de las Vies imaginaires de Schwob, quien contraviene en su obra narrativa dicho enfoque acumulativo y positivista de la historia: de ahí la inclusión en el compendio del autor francés de personajes históricos anónimos, cuyos retratos, por lo demás, no tienen por qué estar sujetos a la verdad, según lo expuesto por el autor en el prefacio, ni tampoco ser ejemplos de virtud o de moral-. Abundando en esta tendencia, Borges, Wilcock y Bolaño pudieron de este modo acometer su particular sátira de los excesos tecnocráticos y culturales del siglo XX, razón por la que considero un acierto la denominación de "fábula biográfica" acuñada por Lorena Amaro (2017), pues incide en su carácter crítico hacia 
las costumbres y los vicios locales, nacionales o personales. La tradición de la "vida imaginaria" encierra, a pesar de todo, ese anhelo por comprender aquello que no se puede comprender realmente, y, pese a las dificultades que plantea el sinsentido humano, constituye asimismo una imaginativa y creadora demostración de que cada biografía "es una forma pasajera y mudable" (Cohen 17), así como un accidentado misterio entre dos fechas azarosas: la de nacimiento y la de muerte. Entre la una y la otra, como dijo el poeta, todos los días son nuestros, inminentemente nuestros.

\section{Obras citadas}

Amaro, Lorena. "De la 'vida de artista' a la 'fábula biográfica': autores quiméricos en las obras de Bolaño, Bisama, Guebel y Pron", en Literatura y lingüística, No 36, pp. 149-175, 2017.

Bioy Casares, Adolfo, y Borges, Jorge Luis. Crónicas de Bustos Domecq. Buenos Aires: Losada, 2003.

Bolaño, Roberto. Amuleto. Barcelona: Anagrama, 2011. La literatura nazi en América. Barcelona: Seix Barral, 2005. 2666. Barcelona: Anagrama, 2004a.

Los detectives salvajes. Barcelona: Anagrama, 2004b.

"Números", Quimera, 166, 1998.

Borges, Jorge Luis. Miscelánea. Barcelona: Random House Mondadori, 2011. Cohen, Marcelo. Música prosaica. Santiago de Chile: Montacerdos, 2016.

Crusat, Cristian. Vidas de vidas. Una historia no académica de la biografía. Entre Marcel Schwob y la tradición hispanoamericana del siglo XX. Madrid: Páginas de Espuma, 2015.

. "La tradición de la 'vida imaginaria': Marcel Schwob y Roberto Bolaño", en Revista de Occidente, No 333, 2009.

Domínguez Michael, Christopher. La sabiduría sin promesa. Vidas y letras del siglo XX. Santiago de Chile: Ediciones Universidad Diego Portales, 2009.

García Jurado, Francisco. Marcel Schwob. Antiguos imaginarios. Madrid: ELR, 2008.

García Jurado, Francisco. "Melancolías y 'clásicos cotidianos': Hacia una historia no académica de la literatura grecolatina en las letras modernas", Tropelías, 12-14, 2001-2003.

Guillén, Claudio. Teorías de la historia literaria, Madrid, Espasa-Calpe, 1989.

Gumpert, Carlos. Conversaciones con Antonio Tabucchi. Barcelona: Anagrama, 1995.

Ibáñez, Andrés. "Sobre antihéroes y tumbas, o por qué Bolaño es grande", Revista de Libros, 8 de enero de 2014. http://www.revistadelibros. com/ventanas/sobre-antiheroes-y-tumbaso-por-que-bolano-es-grande.

Jill Levine, Suzanne. "A universal tradition: The fictional biography", en Review: Literature and Arts of the Americas, volume 7, 1973.

Kermode, Frank. Formas de atención. Barcelona: Gedisa, 1999.

Monterroso, Augusto. Literatura y vida. Madrid: Suma de Letras, 2005.

Pauls, Alan. El factor Borges. Barcelona: Anagrama, 2004.

Praz, Mario. La chair, la mort et le diable dans la littérature du 19 e siècle. Le romantisme noir. Paris: Denoël, 1977.

Reyes, Alfonso. "Teoría de la antología". Obras completas XIV. La experiencia literaria. Ciudad de México: FCE, 1962. 
Schwob, Marcel. El deseo de lo único. Teoría de la ficción. Edición de Cristian Crusat. Traducción de Cristian Crusat y Rocío Rosa. Madrid: Páginas de Espuma, 2012.

Vila-Matas, Enrique. Chet Baker piensa en su arte. Barcelona: Random House Mondadori, 2011.

Vila-Matas, Enrique. El viento ligero en Parma. Madrid: Sexto Piso, 2008.

Wilcock, J. Rodolfo. La sinagoga de los iconoclastas. Barcelona: Anagrama, 1999. 